\title{
Diagnosing the halal industry of Taiwan: a viable system model approach
}

\begin{abstract}
The global halal industry is currently a trillion dollar industry. Businesses around the world are upbeat to get a piece of this lucrative market, including those operating within Muslim-minority contexts. To leverage on this opportunity, there is a need for emerging players to understand the current situation, with the purpose of planning and implementing strategies for the industry's growth. This study examined the Muslim-minority context of Taiwan and utilized the Viable System Model (VSM) as the framework to diagnose the current state of Taiwan's halal industry. Data for the diagnosis were collected mainly through interviews with the relevant agencies, managers or entrepreneurs of halal businesses as well as the consumers of Taiwan's halal products and services. The analysis found that the halal industry in Taiwan already has several implementation units including the Taiwan Halal Center in support of halal business promotion and growth. Taiwan's halal industry has multiple certification bodies co-existing, with several being business-oriented, while the others community-based. The findings also revealed the central role of local-born Muslims and the mosques in facilitating halal certification practices in this Muslim-minority society, indicating a strong foundation in its environment to support the rapid growth of halal industry. Malaysian authority's endorsement of Taiwan's certification bodies is deemed as a crucial support mechanism for their global entry into the halal market. On the whole, the halal industry in Taiwan lacks a formalized halal industry development policy, hence the absence of the functions of policymaking, intelligence, control and coordination in support of a viable halal industry ecosystem. Moving forward, Taiwan needs to institute an integrated halal industry development policy and to fill the missing functions while ensuring cohesions among the functions to manage varieties both in its local as well as in the global environment.
\end{abstract}

Keyword: VSM; Viable system model; Systems perspective; Systemic approach; Halal industry; Muslim-minority society; Taiwan 